\title{
TENDÊNCIAS RECENTES DA URBANIZAÇÃO NA ÁFRICA AO SUL DO SAHARA: NOTAS DE LEITURA
}

ISABEL M. MEDEIROS ${ }^{1}$

Um dos fenómenos mais interessantes na geografia do continente africano, em particular na África ao sul do Sahara (ASS), é a dinâmica rápida, tardia (a partir sobretudo dos anos 1950) e multiforme dos processos de urbanização. As impressionantes concentrações humanas que se impuseram nas paisagens (Lagos na Nigéria poderá ter atingido em 2003, cerca de 10 milhões de habitantes, Kinshasa, os 5,3 milhões, Luanda, já ultrapassou os 2,5 milhões), apresentam, no entanto, nos dias de hoje, tendências de evolução diversificadas, reveladoras de significativas transformações na organização do espaço, da emergência de novas "territorialidades", de modificações nas "velhas" relações cidade/campo, de recomposições nas dinâmicas sociais, em contínua experimentação, da definição de novas "culturas" urbanas.

Com a presente nota pretende-se pôr em evidência alguns dos aspectos recentes da evolução dos "mundos" urbanos e das "urbanidades" na ASS a partir de vários apontamentos de leituras avulsas, centradas especificamente num conjunto de quase uma dezena de contribuições de geógrafos franceses sobre problemas urbanos da Africa contemporânea. Estas, coordenadas por F. Bart, J. Bonvallot, R. Pourtier, foram publicadas na revista Historiens et Géographes, com o título Regards sur L'Afrique, lère partie, n. ${ }^{\circ}$ 379, Juillet 2002. Agrupam-se em dois grandes conjuntos temáticos, acompanhados de diversas referências bibliográficas: o primeiro, L'Afrique du Sud: villes et territoires en devenir, analisa as novas dinâmicas de recomposição territorial e social nas cidades da República da África do Sul (RAS), na sequência da queda formal do apartheid; o segundo, L'Afrique subsaharienne: gestion urbaine et crises, debruça-se sobre alguns dos novos problemas de gestão urbana, derivados da aplicação de medidas de "descentralização" e de boa governance que acompanham as reformas económicas e políticas em curso na maior parte dos países africanos, reportando-se genericamente à ASS ou a casos particulares.

Uma primeira aproximação do fenómeno da urbanização na ASS remete-nos para um olhar sobre as estatísticas disponíveis (em grande parte estimativas), cujas fragilidades e limitações são largamente conhecidas. A expressão quantitativa comparada das dinâmicas urbanas em África, utilizada com frequência nos "fóruns" internacionais e nos media, tem apenas valor indicativo; deve pois ser encarada com grandes reservas.

1 Geógrafa. Investigadora do Centro de Estudos Geográficos da Universidade de Lisboa. E-mail: isamede@gmail.com 
Se é impossível avaliar, com segurança, a dimensão actual do fenómeno urbano na ASS podem, no entanto, evidenciar-se tendências fundamentais. É um facto, sensível à observação, que o volume total da população considerada como urbana, assim como o número de aglomerações e as respectivas dimensões, tem aumentado continuamente, embora com grandes diferenças à escala dos países (fig. 1). Estima-se que, na última década, o ritmo médio anual de crescimento da população urbana na ASS se tenha aproximado de $5 \%$, valor cerca de duas vezes superior ao ritmo médio de crescimento da população total, numa fraç̧ão continental onde a "marca" rural está ainda largamente presente nas paisagens ${ }^{2}$.

Até 2015 as projecções apontam para que o total de urbanos possa registar um aumento de cerca de 6,8 pontos percentuais (o que implica uma duplicação da população em menos de vinte anos) e o número de cidades bimilionárias deva triplicar, admitindo-se que Lagos atinja cerca de 17 ou mais milhões de habitantes, passando a ser a terceira maior aglomeração do planeta.

E tudo se passou em pouco mais de meio século, decisivamente a partir das datas das independências políticas, iniciadas nos fins da década de 50, princípios da de 60 , quando o crescimento das cidades, em particular das cidades capitais, ganhou uma amplitude sem precedentes (as cidades da RAS constituem um caso à parte pois o seu crescimento foi mais precoce).

A construção dos novos Estados e a sua conexão com a ordem global apoiou-se nas cidades capitais, locais de concentração e afirmação dos novos poderes. Desta forma, e através de amplos programas de cooperação internacional, a respectiva importância económica e política viu-se reforçada: os projectos "industrializantes"; as infra-estruturas e os equipamentos realizados; a expansão dos serviços públicos e das representações internacionais; a realização dos símbolos materiais da afirmação do novo Estado; a "africanização" dos quadros, abrindo novas oportunidades de emprego e criando meios de promoção social, à qual se poderia aceder através de relações diversas, em que se liga a "ordem" tradicional com a administrativa, tais como as de "notabilismo" ou "clientelismo" - foram, entre outros aspectos, poderosas alavancas de captação desproporcionada das "forças vivas" de regiões mais ou menos distantes.

As capitais, quase em exclusivo, polarizaram assim importantes fluxos migratórios, compostos essencialmente por uma população jovem, dotada de elevada capacidade reprodutiva, cuja instalação se traduziu no rápido alargamento da área construída, frequentemente de forma descontínua, caótica e improvisada, onde porém muitas vezes a produção espontânea de habitação rivalizava com a oferta pública de alojamentos sociais.

Admite-se que o ritmo médio de crescimento anual entre 1960 e 1980 tenha oscilado entre 5,2\% e 5,6\%, com acentuada amplificação nos anos 80-90 (embora um valor médio escamoteie sempre grandes disparidades regionais) e que o número de cidades milionárias tenha passado de uma em 1960 a doze em 1980 (Dubresson e Raison, 1998: 102).

No entanto, sobretudo desde finais daquela década, princípios da de 90, as estimativas populacionais e vários estudos de caso sobre as dinâmicas registadas nalgumas cidades indiciam que, nas de maior dimensão, se acusa, por vezes de forma ténue, certa desaceleração ou mesmo estabilização do crescimento (Bruneau, 2002). Este, pas-

2 Relatório de Desenvolvimento Humano 2005, PNUD, Nova Iorque. 


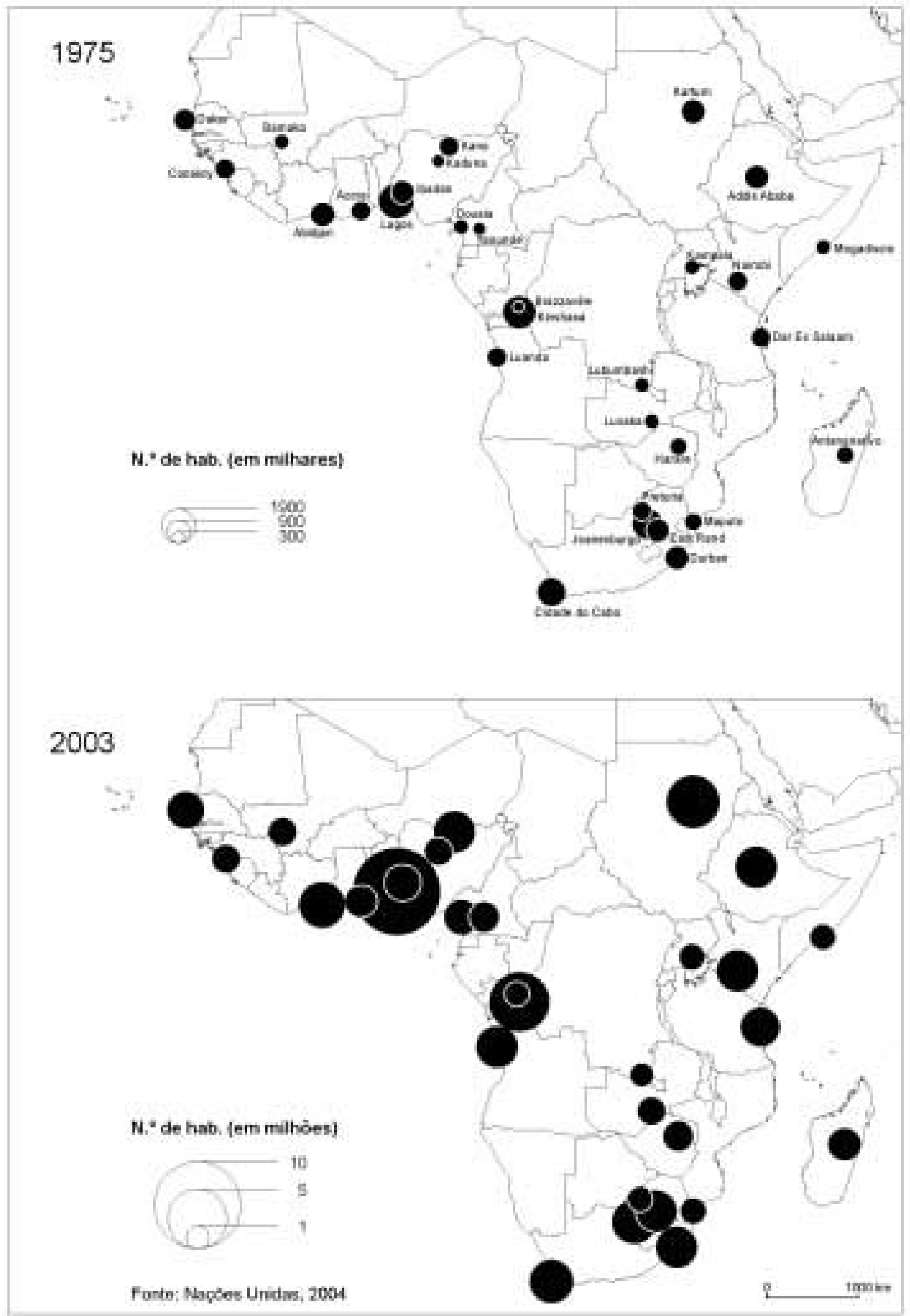

Fig. 1 - Grandes cidades na África do Sul do Sahara: um crescimento rápido e tardio. Fig. 1 - Major urban aglomerations in Africa South of Sahara: a late and fast growth. 
sados os primeiros tempos, em que o saldo migratório era o seu principal motor, deve-se hoje principalmente ao excedente de vidas, em relação com a persistência de taxas elevadas de fecundidade ${ }^{3}$. «Após décadas de crescimento sufocante as grandes cidades parecem demonstrar a necessidade de respirar» (Pourtier, 2001). Excepção à regra, nas grandes aglomerações localizadas em áreas de conflito (Sudão, Etiópia...) ou de pós-conflito, como no caso de Angola ou de Moçambique, o afluxo de "deslocados" dilata consideravelmente o total de residentes urbanos. Estima-se que, por exemplo, em Luanda, entre 1975, na sequência da independência, e 2003, um ano após a assinatura do Tratado de Paz, a população tenha sido acrescida em cerca 2,5 milhões ${ }^{4}$.

Pelo contrário, em várias cidades de pequena e média dimensão, as taxas de crescimento relativo eram mais vigorosas, combinando elevados níveis de crescimento natural com os efeitos de uma alteração de centragem dos movimentos migratórios. Estas dinâmicas populacionais, diferenciadas nos diversos níveis da hierarquia urbana, começaram a notar-se numa altura em que a maior parte dos países africanos se confrontou com uma grave crise financeira. $\mathrm{O}$ desgaste das economias de base "rendeira" (caracterizadas pelo peso excessivo das exportações de matérias-primas em bruto) e de regulação estatal, a passagem de um modelo de acumulação fordista a um outro de acumulação flexível, o despesismo e o "patrimonialismo" revelado pelas elites governamentais, a amplificação do serviço da dívida externa, cuja solvência se foi tornando cada vez mais difícil, embora implícita e complacentemente ignorada pelas organizações internacionais e pelos países dadores até ao seu rápido agravamento na década de 80 , são, entre outros, alguns dos factores estreitamente ligados à sua génese.

A renegociação do serviço da dívida, numa conjuntura internacional, marcada pela emergência de correntes neoliberais e crescente globalização, condicionou a aplicação de medidas de saneamento financeiro, entre as quais as que correspondem a Programas de Ajustamento Estrutural (PAE), sob pressão do FMI e outras instituições (Banco Mundial, Clube de Roma...); procurando introduzir reformas de natureza económica e política (redução do funcionalismo público, redução de salários e de subsídios, encerramento de empresas estatais, privatização/liberalização das economias, subida de preços, desvalorização da moeda...), tais medidas repercutiram-se negativamente no plano social, criando múltiplos disfuncionamentos, particularmente no quotidiano da maior parte dos citadinos, sobretudo nos residentes nas grandes cidades, naturalmente mais expostas.

Apresentando-se até há poucas décadas como fim último de concretização das grandes expectativas de jovens rurais, algumas daquelas aglomerações configuraram-se a partir de então como quadros de dificuldades quase insuperáveis, como locais de "mau viver". Terá sido este sentimento, alimentado no tempo, que desencadeou, em muitos citadinos, vontades de partir. Em alguns países foram detectados fluxos migratórios difusos, de natureza centrífuga, que envolvem todos os que procuram virar as costas a uma "modernidade" a pouco e pouco anquilosada. "Tudo parece passar-se como se os factores que tornavam atractivas as cidades se tornassem entretanto motivos suficientes para as abandonar» (Bruneau, 2002). No entanto, trata-se de um fenómeno que precisa de ser confirmado e aprofundado: as situações são muito diferentes

3 As estimativas do PNUD indicam para o intervalo 2000/2005 valores que oscilam entre 2 nas Maurícias e 7,9 no Níger.

4 Wold Urbanization Prospects. The 2003 Revision. Department of Economic and Social Affairs, UN 2004, New York. 
conforme as cidades e as regiões onde estas se integram, sendo difícil distinguir se se trata ou não de uma verdadeira ruptura relativamente aos mecanismos anteriores de circulação "campo" - cidade, que em muitos casos não foram definitivos e deram origem a um vai/vem, entre cidade e "campo", bastante regular.

Os casos particulares estudados por Bruneau (2002) na República Democrática do Congo (RDC), e na República do Níger, espaço de pastores nómadas e de agricultores, salpicado de pequenas cidades à excepção de Niamey, na altura da independência, são elucidativos das mobilidades referidas atrás e das suas relações com a "crise" económica, social e política que afectou aqueles países na década de 80-90. Na RDC, em Kinshasa, a capital, mas igualmente em cidades médias (tais como os centros mineiros dos planaltos do sul do país), diagnosticaram-se movimentos centrífugos de populações, cujas motivações revelavam uma sentida rejeição da grande cidade. No hinterland mais ou menos próximo procuravam-se novas oportunidades de sobrevivência e de reprodução social, entre as quais as possibilidades de praticar a agricultura, garantindo a subsistência, ou de ter acesso a equipamentos diversos, existentes junto de missões religiosas, ou de pequenas povoações semi-urbanas, ou ainda de outras cidades de reduzida dimensão. Identificaram-se, assim, nas áreas rurais vizinhas, processos de dispersão populacional, em nebulosa ou seguindo os principais eixos de comunicação, de "exurbanização" com difusão de modos de vida urbanos, de novos modelos construtivos, de mentalidades, de vivências, que, usando a expressão criada por Dubresson e Chaléard (1989), se encontram a meio caminho entre o urbano e o rural, «com um pé dentro e outro fora».

Mas a conflitualidade e a desordem reinantes no território, há quase dez anos, provocaram o esvaziamento de algumas cidades, enquanto noutras se verificavam movimentos de concentração brutais, contrariando as mobilidades citadas de sentido inverso.

No Níger, os efeitos da crise económica conjugaram-se com os de secas repetidas nos finais dos anos 60/70 (o que provocara intenso êxodo rural). No termo da década de 80, tal como na RDC, o ritmo de crescimento, sobretudo de Niamey, reduzira-se, ao mesmo tempo que o sistema urbano se renovava por via do dinamismo sentido num número significativo de pequenas cidades onde se cristalizara a maior parte do êxodo rural, embora sejam bastantes os conflitos e tensões suscitadas pela integração dos "neorurais". «Espaços refúgio por excelência... neles foi-se cimentando uma urbanidade diferente, percorrida por tradições seculares mas de grande contemporaneidade porque ajustada às dificuldades actuais». Paralelamente, no exercício das microactividades "informais", entretanto multiplicadas e diversificadas, tinham aumentado as articulações com as aldeias de origem. Esta circunstância traduz o fortalecimento dos laços rural-urbano os quais, na maior parte das cidades africanas, nunca foram radicalmente cortados... e este é um dos aspectos que lhes confere grande singularidade.

As tendências de evolução analisadas mostram estar em curso uma alteração substancial na essência do modelo de sistema urbano herdado do período colonial. Em busca de novos equilíbrios detecta-se um processo de reforço nos níveis inferiores da hierarquia, enquanto nos superiores, nas grandes cidades, o ritmo de crescimento dá sinais de inflexão. Em muitas situações desenvolvem-se "novas" formas de mobilidade cidade-campo (novas relativamente às que caracterizaram a primeira fase do processo de urbanização), cada vez mais complexas e multidireccionais: a importância dos movimentos ditos de "retorno", que não implicam forçosamente regresso ao local de origem mas também não o excluem, ganham expressão, quer correspondendo a mobilidades interurbanas em favor das pequenas cidades, quer projectando as maiores para fora de si 
mesmo. Neste contexto territorial de "margem", fragmentado espacial e socialmente e com fronteiras movediças, onde a cidade se inventa no quotidiano (Piermay, 2002), é grande a mobilidade das famílias, facilitada pela vitalidade das redes de parentesco, pelas recomposições das solidariedades tradicionais e pelos reajustamentos residenciais em função dos acontecimentos do quotidiano. O fenómeno geográfico de "margem", surge assim, quer no âmbito das práticas individuais quer no das remodelações administrativas, estreitamente ligado a processos de "experimentação", onde se descobrem dinâmicas de inovação territorial muito diversificadas. Anthéaume e Giraut (2002) analisaram esta questão a várias escalas, separando a noção de "margem" da de "confim". «A "margem" remete-nos etimologicamente para a ideia de "bordo", de extremidade; as margens existem em relação a um dado espaço administrativo englobando e caracterizando-se pela atenuação dos factores de coerência que definem essa entidade administrativa; em relação ao "centro" traduzem uma atenuação de sentimentos de pertença... embora surjam novas formas de coerência local construídas sobre solidariedades que podem transcender os limites administrativos, muito porosos, e testemunhando capilaridades interactivas...». «O "confim", no plano etimológico, sugere a ideia de limite; existe em relação a uma discontinuidade, a uma separação entre espaços contíguos. Caracteriza-se por um conjunto de limitações derivadas da imposição de uma ruptura que amputa ou dificulta o acesso a recursos e a solidariedades de proximidade, aspectos que contribuem para a sua marginalização». Para se avançar na teorização e explicação dos fenómenos em causa, os autores destacam três ideias força a aprofundar: a necessidade de relativizar sempre o valor de qualquer limite; a importância do jogo institucional; e as diferenças entre os termos citados que, não obstante aplicados frequentemente à mesma situação, não sublinham os mesmos aspectos.

As reformas económicas e políticas que, desde os anos 80, todos os países africanos vão implementando, de forma mais ou menos vigorosa, foram acompanhadas por outras de natureza institucional. Primeiro de descentralização e mais tarde de boa governance, influenciaram decisiva, mas diferenciadamente, a afirmação de novas territorialidades intra-urbanas, com acentuação, em muitos casos, da fragmentação do espaço urbano. Para compreender os processos em curso retenha-se que a noção de fragmentação associa componentes espaciais (desconexões físicas, descontinuidades morfológicas), sociais (segregações residenciais, retraimentos comunitários), económicas e políticas (dispersão crescente dos actores e autonomização dos dispositivos de gestão e de regulação urbanas) (Jaglin, 2001).

Se as palavras chave no plano económico foram e continuam a ser liberalizar/ privatizar, no plano político traduzem-se por descentralizar/desestatizar/democratizar. No quadro das cidades africanas, modeladas por duas lógicas dominantes - a exploração e a segregação - durante algum tempo convergentes, mas inflectidas na sequência das independências políticas que, no entanto, não introduziram uma ruptura vincada, as reformas atrás mencionadas surgiram na sequência da situação de "crise" geral a que aludimos. O espaço ocupado com construções, na sua maior parte de habitação de produção espontânea, alargara-se imenso, sem laços orgânicos entre as suas diferentes partes, carente de infra-estruturas e de equipamentos básicos, ao mesmo tempo que se verificava um empobrecimento geral da maior parte da população com "explosão" das actividades informais. Esta situação demonstra a incapacidade dos governos africanos darem resposta à procura e às necessidades dos citadinos. Os instrumentos de gestão urbana, decalcados dos herdados do período colonial (plano, normas, regulamentos), revelavam- 
-se desajustados das realidades: a rapidez da extensão e da fragmentação da área urbanizada e a grande pobreza das famílias, dificultavam a respectiva operacionalidade, problema exacerbado pela falta de meios financeiros e pela instabilidade política.

A descentralização dos financiamentos e da gestão urbana, impulsionada pelas instituições dadoras e pelo Banco Mundial, apresentou-se como meio de contornar as dificuldades enunciadas, lutando contra o peso excessivo do Estado, considerado por aquelas instituições como principal factor de bloqueio ao desenvolvimento e à democratização. Tornava-se imperativo corporizar políticas localizadas, susceptíveis de produzir grandes mudanças sociais mas... exigindo avultados financiamentos, numa conjuntura marcada pela liberalização/privatização das economias, num quadro institucional em mutação e com recursos limitados, seriam exequíveis?

No início dos anos 90 o discurso político introduziu um novo conceito (já antigo no pensamento anglo-saxónico), o de "bom governo" e de boa governance (reunião dos vários processos de coordenação de actores, grupos sociais e instituições envolvidos na realização de projectos urbanos colectivamente negociados). Esta orientação complementa as de natureza macroeconómica, ditadas em particular pelo Banco Mundial: o incremento da participação dos particulares, quer pela via da privatização, quer pela via associativa, constitui uma forma de transferir funções e mesmo responsabilidades até então asseguradas pelo Estado (que é olhado com desconfiança por aquela organização), ao qual se reserva apenas o papel de regulador e facilitador. «O recurso à governance não é mais do que o reconhecimento explícito dos sistemas de actores e de processos que, fora da esfera do Estado, asseguram, de facto e desde há muito, a regulação dos mecanismos de urbanização nas cidades africanas, onde 40 a $70 \%$ dos citadinos vivem em bairros ilegais e dependem de empregos informais» (Dubresson e Jaglin, 2002: 162). A maior autonomia assim concedida às colectividades locais tem importantes repercussões na organização do espaço urbano. A recomposição das práticas de gestão condicionou uma redistribuição espacial das responsabilidades, com reconfiguração dos perímetros de acção colectiva em função de interesses e diversas coligações. Estes processos de mudança levantam um conjunto de questões no plano da urbanização: «será que as novas modalidades de gestão urbana atrás mencionadas constituem uma resposta adequada à crescente diferenciação dos citadinos? Será que tornam as cidades mais governáveis ou pelo contrário acentuam uma gestão "em arquipélago"? Será que favorecem a integração ou alimentam um processo de fragmentação urbana?» (Dubresson e Jaglin, 2002: 161-184).

Encontrar as respostas adequadas não é tarefa fácil, exigindo naturalmente aprofundamento da investigação neste domínio, que não deverá subestimar o papel mais ou menos visível das autoridades "tradicionais". No entanto, a análise da evolução registada no exercício da gestão urbana local, embora com orientações extremamente variadas, permite retirar algumas conclusões.

A articulação das iniciativas individuais, partilhadas por associações, ONGs, privados, com os dispositivos institucionais de gestão, não seguiram um modelo fixo; a descentralização/privatização/participação e os princípios de governance foram assim localmente reapropriados e combinados de maneira diferente, dando origem a grande variedade de "complexos reformadores", cujas consequências são muito diversas conforme a respectiva estrutura organizativa. As colectividades locais, frequentemente desprovidas de meios, perante a complexidade das tarefas a empreender, dos objectivos a alcançar e da diversidade dos segmentos sociais a envolver, tendem para a especialização e a espacialização das acções, direccionando-se na procura de cooperações $a d$ hoc. A situação mais frequente é a generalização, se bem que diferentemente configu- 
rada, da externalização crescente das funções, em direcção a parceiros e dispositivos vários, relacionadas sobretudo com a realização dos equipamentos e o fornecimento de serviços urbanos. Se a privatização corresponde a uma opção largamente assumida, não está completamente generalizada, notando-se grandes diferenças conforme os tipos de serviços prestados, os bairros, as competências e a capacitação dos poderes locais. Emergem assim demarcações mais ou menos vincadas nos espaços urbanizados: os territórios das clientelas solventes, dos mais ricos, que utilizam a privatização como meio de sublinhar a separação no corpo da cidade (serviços de segurança privados, de abastecimento eléctrico...), opõem-se assim aos dos mais pobres, categoria no entanto muito heterogénea, o que determina grande variedade de desempenhos. O recurso ao associativismo/comunitarismo, congregando competências e outros meios, de ONGs, missões religiosas e entidades diversas, operando por conta de projectos financiados do exterior, ou no âmbito de geminações com cidades estrangeiras, ou mesmo no de outras cooperações bilaterais, é o caminho mais correntemente seguido nas "ilhas" de residência dos mais desfavorecidos para resolver os vários problemas.

Em grande número de países, com algumas excepções, tais como a Etiópia ou o Sudão, por exemplo, a regulação estatal (quadro legal recobrindo regulamentos e procedimentos de enquadramento enunciados pelos poderes públicos) tem-se vindo de facto a retrair, embora o poder das colectividades locais não esteja consolidado, por falta de meios e competências. A este nível, a atomização dos meios e processos de gestão técnica, a pluralidade das estruturas e dos operadores com estatutos diferentes, suscitam muitas vezes acesa competição intra-urbana pelo acesso a um projecto ou a outros recursos; favorece-se assim a territorialização dos dispositivos de gestão, e a multiplicação dos sistemas locais de regulação, fundamentada quase sempre em condições de clientelismo e de patrimonialismo (Jaglin e Dubresson, 1993: 162), ameaça a coesão social e o funcionamento da cidade como um todo.

As novas "territorialidades" emergentes na maior parte das cidades africanas (extremadas nas da RAS) sobrepõem-se frequentemente a formas de segregação mais antigas; embora em muitos casos se tenham esbatido, recompõem-se, acompanhando-se de intensas diferenciações socioeconómicas, sobretudo nos bairros onde as famílias são mais afectadas pela "crise"; "segregação e fragmentação alimentam-se uma à outra» (Dubresson e Jaglin, 2002: 165).

Mas as situações consideradas não estão rigidamente fixadas, havendo sinais de movimentos de sentido contrário, de "contra-fragmentação". A importância crescente dos actores externos no financiamento e enquadramento dos projectos, assim como a necessidade de integrar e coordenar diferentes agentes com interesses divergentes no quadro da cidade vista como um todo colectivo, são questões que vêm conferindo de novo ao Estado, embora de modo leve e desigual, certo papel interventor, encorajado pelo Banco Mundial: destaque-se a elaboração de documentos de planeamento e o controlo da sua aplicação, determinadas intervenções fundiárias, articulações, por exemplo, de parcerias público-privadas (tais como entre associações citadinas de produtores e de comerciantes e ONGs), desenvolvendo actividades e funções estruturantes para as sociedades locais.

A análise dinâmica do mercado fundiário (Bertrand, 2002: 171-184) de que o Banco Mundial, grande financiador de projectos urbanísticos, encoraja a privatização, reflecte bem as suas relações com as questões de demarcação territorial, de promoção versus diferenciação da sociedade civil e de participação dos diferentes actores urbanos que se mencionaram. Em dois contextos diferentes - a cidade de Bamako no Mali, onde a herança do centralismo burocrático francês dificulta a sua flexibilização, com 
envolvimento das colectividades locais representativas e com a organização de parcerias, e a cidade de Accra, no Ghana, onde o indirect rule britânico permitiu reconhecer juridicamente a propriedade comunitária no âmbito do direito consuetudinário verifica-se que, neste último caso, o embutimento de prerrogativas sobre territórios onde o poder dos chefes de terra "tradicionais" é ainda muito forte e a intensa contestação de direitos sobre o solo dão azo a permanente conflitualidade, entrave poderoso no plano da gestão urbana, da descentralização e da participação dos representantes locais na coordenação das necessidades da cidade.

As transformações mais radicais nas dinâmicas de urbanização na ASS estão em curso nas cidades sul-africanas, verdadeiro paradigma do modelo urbano colonial segregado - «a projecção de um ideal metropolitano num espaço olhado e concebido como tábua rasa» (Messiah e Tribillon, 1987). Espontânea ou deliberadamente assumidas, na sequência da queda formal do apartheid e da realização das primeiras eleições pluriraciais em 1994, reflectem a necessidade de "refazer" um país, com desmantelamento de fronteiras racialmente estabelecidas, ponto de partida para um longo caminho visando atingir uma profunda alteração dos legados do passado.

Marcadas vincada e duradouramente pela segregação do território ditada pela cor da pele, institucionalizada por governos coloniais de minoria branca e levada ao extremo com o sistema de apartheid (1948/1991), conhecem nos dias de hoje uma evolução com efeitos contraditórios: se, por um lado, se procuram anular as heranças de um urbanismo racista, ainda bem visível, quer nas formas, quer nos comportamentos dos vários segmentos da sociedade civil, por outro, verificam-se novas segregações e fragmentações, algumas das quais decorrentes das escolhas em matéria de gestão urbana, «indissociáveis da reorganização e recomposição dos poderes urbanos» (Jaglin, 2001: 244).

A discriminação racial considerada como base da organização da sociedade e do espaço, instrumentalizando o território como fronteira entre os vários grupos, ditou nas cidades a separação dos locais de residência (em que a construção de townships ${ }^{5}$ foi um dos elementos mais emblemáticos), no acesso ao trabalho, aos serviços, nas mobilidades intra-urbanas e no direito fundiário. Os projectos de construção de townships foram amplamente incrementados na sequência da subida ao poder do Partido Nacionalista em 1948, dado o afluxo de população negra às cidades, criadas pelos brancos e para os "não brancos". Análises históricas recentes, suportadas no estudo de documentação e de discursos oficiais de tipo paternalista do após guerra, permitem inferir que «os townships do apartheid são "cidades-jardim" simultânamente pervertidas e perversas. Pervertidas porque o projecto utópico, aliás criado por Ebenezer Howard, transformou-se aqui numa contra utopia cuja lógica se vira contra o homem; perversas porque a utopia nasceu no "ovo da serpente": foi logo na sua concepção que os valores utópicos se alteraram radicalmente» (Dagorn e Guillaume, 2002: 115-124). Nos textos justificativos daqueles projectos, o termo township não aparece citado ao contrário do de "cidade jardim", encontrando-se referências à necessidade de criar «quadros de vida completos», para «...estas massas desordenadas de trabalhadores a agrupar em comu-

5 O termo township aplica-se genericamente às áreas residenciais para a população "não branca", compostas quase sempre por habitações unifamiliares, dependentes de autoridades de administração local específicas. As municipalidades urbanas abrangiam apenas os sectores residenciais dos brancos e os de actividade económica. 
nidades felizes e bem alojadas de modo a poderem finalmente conhecer a paz física e espiritual». Todavia, na prática, "as utopias"(?), traduziram-se na realização de conjuntos habitacionais monótonos, fragmentos distantes do centro - a população de origem africana seria tolerada na cidade dos brancos mas bem distanciada - sobreocupados, sem espaços verdes e equipamentos, cuja dinâmica era a antítese da própria "urbanidade", entendida como espaço de encontro, de sociabilização.

Nas últimas décadas de apartheid, houve algumas alterações no que concerne às liberdades de circulação e mesmo de acesso à propriedade fundiária e imobiliária fora das áreas exclusivas de residência. As populações "não brancas" puderam assim formalmente penetrar em sectores urbanos que lhes eram proibidos; todavia, os efeitos concretos da mobilidade permitida foram modestos embora se tenha notado certa diversificação construtiva em townships, principalmente nos afectos às comunidades indianas e coloured $^{6}$, função de factores de natureza socioeconómica.

A partir de 1991 multiplicaram-se as medidas que claramente demonstram a vontade política de desfazer a fragmentação/segregação herdada, bem como a exclusão política da maior parte da população negra (abolição da segregação imposta por lei e de outras restrições em matéria habitacional, aplicação da lei de mercado sem limitações raciais às transacções imobiliárias, o que permite às famílias de maior rendimento adquirir habitação em qualquer bairro, construção maciça de habitação social principalmente em áreas periféricas na proximidade das townships existentes, a fim de minimizar encargos financeiros...); tinha-se como objectivo a integração social, a igualização de acesso aos recursos urbanos com redefinição das divisões administrativas e reforço do poder local (eleições municipais em 1995). No entanto, o espaço contém imensas forças de inércia que explicam as resistências e mesmo as oposições surgidas relativamente às mudanças territoriais desejadas. Mainet-Valleix (2002), num estudo sobre a comunidade indiana na cidade de Durban, província de KwaZulu-Natal (em 1998 representava cerca de $20 \%$ da população da cidade e até 1984 aquela província foi a única onde os indianos podiam residir), mostra bem como a segregação imposta na base de uma "identidade" definida pelo poder, foi, em muitos casos, parcialmente recomposta, por via endógena. As townships destinadas a alojar aquelas populações, situadas muitas vezes a cerca de 30/40 quilómetros do centro, tornaram-se em parte espaços vividos, "ilhados" relativamente aos dos outros grupos, que se articulam em rede, num tecido urbano fragmentado e para muitos deliberadamente desconhecido, fora dos seus territórios construídos. A disponibilidade do automóvel particular e das redes de transportes colectivos facilita a espacialização das práticas citadinas, condicionando representações urbanas em que a cidade é feita de fragmentos de "lugares", (os territórios vividos) e de "não lugares" (a maior parte dos bairros dos "outros" e dos espaços públicos onde as pessoas se cruzam sem entretecer laços sociais).

Os comportamentos analisados para a comunidade indiana são passíveis de se verificar, com certo grau de particularismo, noutras comunidades: as grandes diferenças socioeconómicas suscitadas pelo apartheid, extremadas na polarização de comunidades negras-comunidades brancas, não se alteram por vontade política, continuando ainda a agir como factor limitante a processos de dessegregação. «Como a vasta maioria da população negra era extremamente pobre e incapaz de comprar propriedades nas

6 Os Coloured constituem um grupo muito heterogéneo, fruto de mestiçagens diversas e melhor representados na província do Cabo. 
“áreas brancas”, não é de surpreender que a população branca defenda os seus territórios com elevado nível de sucesso» (Cristopher, 2001).

Conclui-se deste modo que a abertura proposta para uma sociedade dividida, com eliminação de fronteiras, deu lugar em muitos grupos a um reforço da importância dos seus territórios de sociabilidade comunitária, vistos como os melhores "redutos" capazes de oferecer segurança em período de viragem política. A aprendizagem de um "viver em conjunto" continua ainda bastante por efectivar, assim como a capacidade colectiva de manter relações de proximidade em populações fortemente diferenciadas. O princípio da "separação" residencial persiste, embora ganhando novos contornos, «porque os mecanismos de diferenciação actuais estão menos conectados com o sistema anterior de referência; não quer dizer que a "pertença" racial tenha perdido significado mas há outros critérios de agrupamento/demarcação que se sobrepõem recompondo as segregações em função de esquemas mais complexos» (adaptado de Jaglin, 2001). A sua alteração depende muito das políticas públicas a operacionalizar à escala local, mas também do investimento de cada citadino: a ascensão rápida de uma classe média negra, a frequentação dos espaços comerciais do centro por todos os grupos populacionais, são factores que tendem a contrariar as "descontinuidades" citadas, favorecendo a integração.

A título de exemplo considere-se a evolução verificada na cidade de CapeTown. Fundada em 1652, numa base dual assinalada no espaço «pela plantação de uma sebe de amendoeiras amargas destinada a separar a área afecta aos europeus, onde se situam o forte e as hortas, do continente africano» (Houssay-Holzschuch, 2002) é considerada a "cidade-mãe" dos colonos europeus. A dicotomia patente na organização do espaço rapidamente se complicou dada a emergência de um grupo populacional, fruto de mestiçagens, os coloured (actualmente constituem a maior parte da população da cidade), e pela entrada de outras populações com origens diversas, entre as quais muitas provenientes da Índia. Se até 1948 a segregação residencial apenas foi imposta à população negra, a partir daquela data as orientações políticas anteriores alargaram-se e sistematizaram-se. Com o fim do apartheid desenharam-se diversas e complexas tendências de mudança no plano socioespacial e residencial. Os bairros pericentrais, alguns com construções fortemente degradadas que, de acordo com o Group Areas Act (GAA) de 1950, eram locais de residência de população branca, depois de uma primeira fase de forte mistura racial, verificada mesmo antes de 1991, acolhem hoje sobretudo população negra e famílias coloured de baixos rendimentos. Nas áreas residenciais de "brancos", mais afastadas do centro antigo, a integração doutras populações revela-se lenta, atendendo aos elevados valores atingidos pela propriedade imobiliária; apenas alguns segmentos privilegiados, no âmbito das transferências do poder político, aí vão penetrando. Nas periferias cresceram as habitações "espontâneas", produzidas no quadro de circuitos informais, embora a partir de 1996 os bairros de habitação social se multiplicassem; se bem que patenteiem um modelo morfológico semelhante ao da township, apresentam diferenças de conteúdo, sensíveis na diferenciação racial neles existente (famílias coloured e africanas desfavorecidas, inscritas nas listas de procura de habitação) ainda que denunciando um novo tipo de segregação - a de natureza social. Em muitas áreas residenciais construídas recentemente para classes médias, a diversidade racial também é clara, e reveladora da ascensão social de segmentos populacionais anteriormente segregados - sobretudo indianos, coloured e alguns africanos. "A dessegregação racial no plano residencial está limitada e pode ou não acompanhar-se de segregação social. Pontualmente casos de ressegregação racial existem... Ora para melhor apreender as mudanças em curso importa reflectir 
em sentido mais amplo sobre a noção de segregação» (Houssay-Holzschuch, 2002: 131). Saff (1998) propõe diferenciar o que designa por "dessegregação" em sentido restrito e o que prefere designar por "desracialiazação": este termo aplica-se, por exemplo, à escala de um bairro em que residem populações com grandes diferenças de raça e rendimento (instalação de ocupantes, negros, em situação de grande precariedade habitacional em bairros historicamente de brancos), entre as quais persiste forte segregação funcional, social e espacial; a "desracialização" recobre assim, num conteúdo pluriracial, a existência de rupturas - o viver lado a lado pode dar azo ao endurecimento de atitudes. Já à escala mais reduzida, a do quarteirão, aquelas rupturas não são sentidas. O termo "dessegregação" é reservado por Saff para designar processos de dessegregação efectivos, isto é, aqueles em que a ruptura desapareceu, qualquer que seja a escala de análise. Esta posição conduz a considerar outras formas de segregação para além das residenciais: as que se manifestam nas práticas sociais, aspectos relevantes na definição das "urbanidades" (Lévy, 2000), entendidas como resultante de uma multiplicidade de encontros e reencontros possíveis.

Os processos de mudança que se enunciaram não são mais do que dinâmicas em aberto, não concluídas, com consequências imprevisíveis. Os mecanismos geradores das descontinuidades de vários tipos e que se têm acentuado em muitas cidades, confrontam-se, frequentemente, com forças de sentido contrário, quer espontâneas quer dirigidas, favorecendo a integração. Determinar, à escala das aglomerações, o peso relativo destas e daqueles é tarefa difícil, assim como a de avaliar o resultado das imbricações produzidas em conjunto, na dinâmica dos territórios. Está-se perante uma fase de complexificação e de grande diferenciação do espaço das cidades africanas, campo aliciante para a investigação geográfica.

\section{BIBLIOGRAFIA}

Anthéaume B, Giraut F (2002) Les marges au cœur de l'innovation territorialle? Regards croisés sur les confins administratifs (Afrique du Sud, France, Maroc, Niger, Togo...). Historiens et Géographes. Revue de L'Association des Professeurs d'Histoire et Géographie, 1ère Partie, 379: 133-152.

Bertrand M (2002) Gestion foncière et logique de projet urbain: expériences comparées en Afrique occidentale francophone et Anglophone. Historiens et Géographes. Revue de L'Association des Professeurs d'Histoire et Géographie, 1ère Partie, 379: 171-184.

Bruneau J (2002) Vivre la ville à la campagne: crises des sociétés et exurbanisation en Afrique tropicale. Historiens et Géographes. Revue de L'Association des Professeurs d'Histoire et Géographie, 1ère Partie, 379: 185-197.

Bart F, Bonvallot J, Pourtier R (2002) Regards sur L'Afrique. Historiens et Géographes. Revue de L'Association des Professeurs d'Histoire et Géographie, 1ère Partie, 379: 97-226.

Chaléard J-L, Dubresson A (1989) Un pied dedans, un pied dehors. A propos du rural et de l'urbain en Côte d'Ivoire. Tropiques. Lieux et Liens, ORSTOM, Paris: 277-290.

Cristopher A J (2001) Urban segregation in post apartheid South Africa. Urban Studies, 38(3): 449$-466$.

Dagorn R, Guillaume R (2002) Howard et les pervers. Une utopie sud africaine. Historiens et Géographes. Revue de L'Association des Professeurs d'Histoire et Géographie, 1ère Partie, 379:115-124. 
Dubresson A, Jaglin S (2002) La gouvernance urbaine en Afrique Subsaharienne. Pour une géographie de la régulation. Historiens et Géographes. Revue de L'Association des Professeurs d'Histoire et Géographie, 1ère Partie, 379:161-184.

Dubresson A, Raison J P (1998) L'Afrique subsaharienne. Une Géographie du changement. A. Colin. Paris.

Frérot A-M (dir.) (1999) Les grandes villes d'Afrique. Ellipses, Paris.

Gervais-Lambony P, Jaglin S, Mabin A (dir) (1999) La question urbaine en Afrique Australe. perspectives de recherche. Karthala, IFAS, Paris.

Houssay-Holzschuch M (2002) Ségrégation, déségrégation, reségrégation dans les villes sud africaines: le cas de Cape Town. Historiens et Géographes. Revue de L'Association des Professeurs d'Histoire et Géographie, 1ère Partie, 379: 125-133.

Jaglin S (2001) Villes disloquées? Ségrégations et fragmentation urbaine en Afrique Australe. Annales de Géographie, 619: 243-265.

Jaglin S, Dubresson A (1993) Pouvoirs et cités d'Afrique Noire. Décentralisations en question. Karthala, Paris.

Lévy J (2000) Le tournant géographique: penser l'espace pour lire le monde. Bélin, Paris.

Mainet-Valleix H (2002) Ségrégations et territoires urbains dans une métropole sud africaine. Quelques réflexions à partir des communautés indiennes de Durban. Historiens et Géographes. Revue de L'Association des Professeurs d'Histoire et Géographie, 1ère Partie, 379:103-114.

Messiah J, Tribillon F (1987) Villes en développement. La Découverte, Paris.

Pourtier R (2001) Afriques Noires. Hachette, Paris.

Piermay J L (2002) L'Invention de la ville sud-saharienne. Historiens et Géographes. Revue de L'Association des Professeurs d'Histoire et Géographie, 1ère Partie, 379: 153-159.

PNUD (2005) Relatório de Desenvolvimento Humano. Nova Iorque.

Saff G R (1998) Changing Cape Town: urban dynamics, policy, and planning during the political transition in South Africa. Lanham, University Press of America.

United Nations (2004) World Urbanisation Prospects. The 2003 Revision. Department of Economic and Social Affairs, New York. 